In November 1933, a flashover took place from the end windings of the alternator to the station frame, and simultaneously a flashover to earth occurred from one terminal on the main oil circuitbreaker controlling the altermator. An examination showed that the path of the flashover in the stator windings passed through at least $4 \mathrm{in}$. of air, and it was computed that it could only have been caused by an over-potential exceeding $70 \mathrm{kv}$. The normal operating potential of the winding to earth at the point of the fault was $6.5 \mathrm{kv}$. When the flash occurred, the alternator was isolated from the transmitting system and had just been excited to normal voltage prior to being synchronized with the main busbars.

The characteristics of the voltage transformers and of the capacitance of the alternator windings and their connecting cables showed that the conditions which gave rise to the phenomenon known as neutral instability were present. It was calculated that the potential of the windings cable and switchgear could build up to $75-100 \mathrm{kv}$., which agreed closely with the value deduced from the examination of the failure from the available data.

While the satisfactory operating experience'with the concentric-conductor winding proves the construction to be sound, investigations following the failure of a joint showed that a number of improve- ments were possible. A new technique has been developed for the making and insulating of joints. Among other improvements is the use of glass silk as an insulating material. It is also being used in place of cotton or silk for other purposes. It is more durable and will withstand a higher temperature, and the individual fibres, being solid, cannot absorb moisture.

The earthing of systems through a tuned reactor or are-suppression coil has received great attention in Great Britain in recent years and is being given a trial on a number of systems. As the coil has a comparatively high impedance, circulating currents due to harmonics should be negligible, and therefore it would be permissible to earth the neutral point of a generator by this means.

Experience has shown that the damage which is caused by an earth fault in an alternator is small, as the differential protection trips both the main and the neutral breakers very rapidly, thus interrupting the fault circuit. A fault between phases causes greater damage, as the fault circuit cannot be interrupted, and although the field circuit may be opened rapidly, an appreciable time is required for the main flux to collapse.

Mr. Horsley concludes by emphasizing the trustworthiness of concentric-conductor alternators, and thinks that they have a promising future.

\title{
NATIONAL FRUIT AND CIDER INSTITUTE
}

$\mathrm{T}$ HE annual meeting of members of the National Fruit and Cider Institute was held at the University of Bristol Research Station, Long Ashton, on June 27.

Chief among the items of interest were exhibits arranged by the Fruit Products Section dealing with methods of using fruit products to alleviate the difficulties occasioned by the sugar shortage. During the War of 1914-18, Prof. B. T. P. Barker organized a scheme for the conversion of apple juice into jelly. This work has been taken up again and extended by Mr. V. L. S. Charley, who has developed methods for concentrating fruit juices by vacuum evaporation. The acid content of the raw juice is first reduced by the use of potassium carbonate or pure chalk at a rate of 2-3 lb. per 100 gallons of juice. Acid cooking apples as well as dessert varieties can thus be converted into very sweet concentrates. The apple flavour is retained by recovering the volatile products during concentration and returning them to the concentrate. Treatment of the juice before concentration with a pectin-decomposing enzyme allows a high degree of concentration without danger of gelling, and the final product assumes the consistency of treacle, containing about 75 per cent soluble solids and 65 per cent invert sugar. One ton of cull apples produces 150 gallons of juice, which is concentrated to make 13 gallons of treacle.

Apple treacle has been successfully used as a sweetening agent for both domestic and industrial preparations such as jams, cakes, confectionery, cider and pickles. All kinds of excellent jam have been made by using half the normal amount of sugar with an equal quantity of apple treacle. The treacle itself is self-sterile and can be stored without special con- tainers. Apple jelly is made by warming the concentrated juice with one tenth its volume of liquid apple pectin and adding a small amount of sugar. Plum concentrate has also been prepared, but its high acidity renders it less suitable for general use. A fuller account of this work appears in Food Manufacture, 15, 6 (June 1940) and in the Long Ashton Annual Report for 1939.

Another exhibit showed methods of maintaining the natural sugar in cider. The usual procedure is to allow the apple juice to ferment and to add sugar to the final product. By adding potassium metabisulphite as a source of sulphur dioxide and removing yeasts by. centrifuging, fermentation can be suspended and much of the original sugar content retained.

A phase of the Station's work on plant nutrition was represented by an exhibition of vegetable and other crop plants suffering from manganese deficiency. This deficiency, recognizable by a chlorotic condition and yellowing of the foliage, has occurred with some frequency in oats sown on newly ploughed grassland, especially on highly calcareous soils. Garden beets, spinach beet, spinach, parsnips and lettuce have been found showing similar symptoms when grown in soil to which much lime and organic matter has been added. Successful control is being achieved in some cases by spraying the foliage with a dilute solution of manganese sulphate.

The Station plantations were open for inspection by the visitors. Considerable interest was shown in demonstration plots on which the cropping plans recommended in the Ministry of Agriculture Grow. more Bulletin No. 1 are being subjected to practical tests. 